\title{
Meconium Aspiration Treated with Extra-Corporeal Membrane Oxygenation
}

\author{
Iqbal Mustafa, Syarif Rohimi, Soemanto, Embing Sjamsudin, Hartoyo, Heru \\ Samudro, Jusuf Rachmat, "Budining Wirastari, ”Edi M. Halimun, Zuswahyudha, \\ Anna Ulfah Rahayoe
}

('Harapan Kita' National Cardiac Center, and * 'Hlarapan Kita' Maternity and Child Hospital, Jakarta)

\begin{abstract}
We report the first Indonesian baby delivered by cesarean section and developed into metabolic acidosis, severe respiratory failure due to meconium aspiration accompanied by right pneumothorax. The case was successfuly managed with extracorporeal membrane oxygenation (ECMO). [Paediatr Indones 1998; 38:273-278]
\end{abstract}

\section{Introduction}

Extracorporeal membrane oxygenation (ECMO) is an extracorporeal life support (ECLS) system which provides prolonged but temporary (1-30 days) support of the heart or lung function using mechanical devices. ECMO is a specific term of ECLS when this mechanical support is used with extrathoracic cannulation for respiratory support. ${ }^{1}$ The successful use of ECMO in management of neonatal respiratory failure was reported for the first time by Bartlett in $1975 .{ }^{2}$ ECMO is also used as an adjunct to repair congenital heart disease in neonatal and pediatric patients, and a useful technique in managing infant with congenital diaphragmatic hernia. ${ }^{3,4}$ The impressive increased survival of acute respiratory failure associated with ECMO technique in newborns had been shown. Currently, in the United States ECMO is considered as a standard therapy in neonatal respiratory failure. ${ }^{4}$

Author's address: Dr. Iqbal Mustafa, Intentive Care Unit, 'Harapan Kita' Cardiac Center, Jalan Jenderal S. Parman, Jakarta, Indonesia. 


\section{Report of the Case}

A female full-term baby of 12 hours old with body weight of $3400 \mathrm{~g}$ was referred to the Intensive Care Unit, 'Harapan Kita' National Cardiac Center from 'Harapan Kita' Maternity and Child Hospital. The patient was delivered by cesarean section, and she then developed severe asphyxia and metabolic acidosis leading to severe respiratory failure. Chest $\mathrm{x}$-ray film revealed the appearance of meconium aspiration accompanied by right pneumothorax. The baby looked severe ill and comatous, dyspneic, cyanotic and runny nose. Heart rate was $148 / \mathrm{min}$, blood pressure $70 / 50 \mathrm{mmHg}$ and temperature within normal limit. Skull, fontanels, heart, abdomen and extremities showed no abnormalities. Peripheral blood examination showed that hemoglobin was $17.8 \mathrm{~g} / \mathrm{dl}$, white blood count $24.500 / \mu \mathrm{l}$ and platelet $277.000 / \mu \mathrm{l}$.

The patient was treated with intravenous maintenance fluid and cefotaxime of $2 \mathrm{x}$ $150 \mathrm{mg}$. Her respiratory system was supported with controlled mechanical ventilation. A water sealed drainage was inserted on her right hemithorax. After a follow-up of 12 hours, the baby was still cyanotic even under mechanical ventilation with $\mathrm{FiO}_{2}$ of $100 \%$. Arterial blood gas analysis showed a worsening to $\mathrm{pH} 7.15, \mathrm{PO} 249$ (with $\mathrm{FiO}_{2}$ of $100 \%, \mathrm{PCO}_{2} 51, \mathrm{HCO}_{3} \mathrm{BE}-10 \mathrm{mEq} / \mathrm{L}$, and $\mathrm{O}_{2}$ saturation of $72 \%$. Based on these data, oxygenation index (OI) was 0.88 . Since this was one of entry criteria for ECMO candidate, the patient was referred to the ICU, 'Harapan Kita' National Cardiac Center. ECMO was performed through inferior jugular vein and right carotid artery for 80 hours. The patient showed an improvement and was extubated on the third day without any complication. She was then sent back to "Harapan Kita" Maternity and Child Hospital in good condition. Currently, she is three months old and her growth is compatible with her age.

The following is the brief description of ECMO procedure used in this patient.

\section{Circuit}

The ECMO perfusion circuit consisted of a Sci-Med membrane lung (Life Systems Inc, Minn) a Bio-Medicus pump (Bio-Medicus, Eden Prairie, Minn) and silicone rubber tubings. See Figure 1. The blood was drained via a single 12 Fr right atrial cannula (Stockert Corp, Munich, Germany) which was introduced via the right appendage. The oxygenated blood was returned through an $10 \mathrm{Fr}$ ascending aortic cannula (Stockert Corp, Germany). For anticoagulation, heparin was titrated to maintain an ACT in the range of $170-200$ s. Platelet were transfused to achieve platelet counts $>50.000 / \mu 1$.

\section{ECMO Course}

The pump flow ranged from 300 to $500 \mathrm{ml} / \mathrm{min}$. The gas flow within the hemodynamic status was improved. The inotropic support was reduced dobutamine $5 \mathrm{mEq} /$ $\mathrm{kg} / \mathrm{min}$. During ECMO, mean arterial pressure ranged from $30-40 \mathrm{mmHg}$ central venous pressure from $8-10 \mathrm{mmHg}$. 


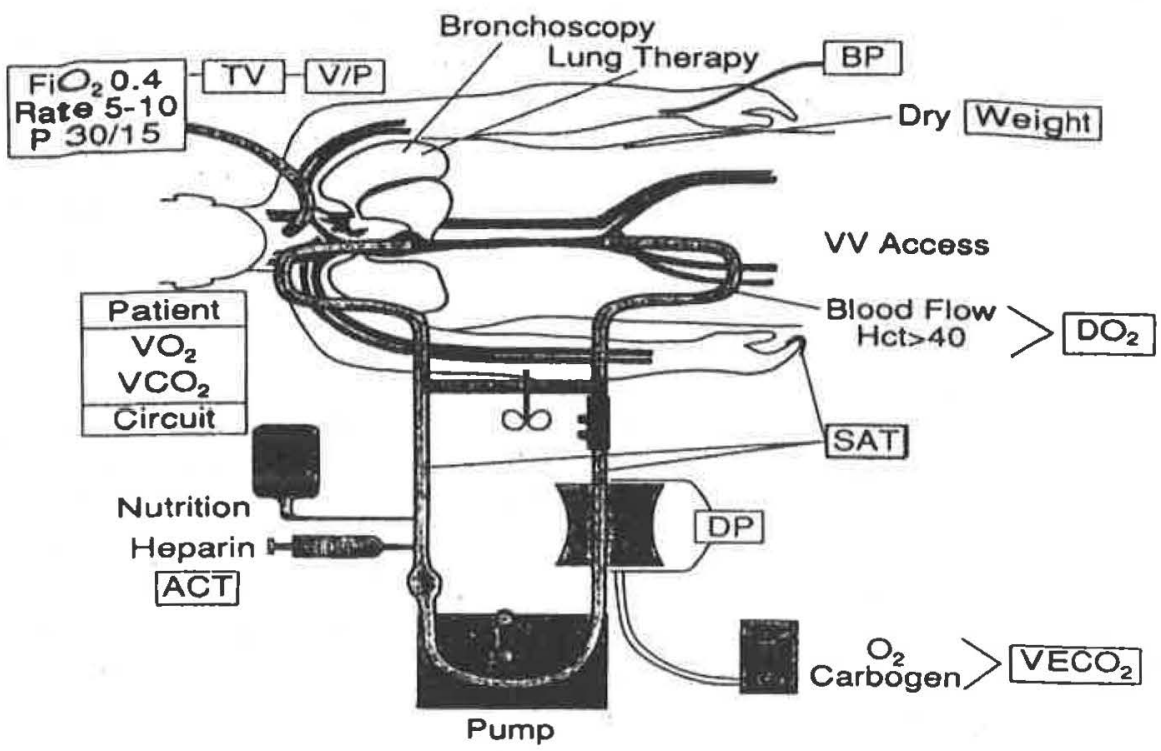

Figure 1. Extracorporeal membrane oxygenation circuit

The ventilatory rate was reduced for 20 to $10 / \mathrm{min}$, and the peak inspiratory pressure from 25 to $20 \mathrm{mmHg}$. The $\mathrm{FiO}_{2}$ decreased from $100 \%$ to $21 \%$. Monitoring of saturation of arterial oxygen with oxymeter pulse was necessary. Table 1 summarizes the course of the illness during ECMO support.

\section{Discussion}

Meconium aspiration constitutes one of the major causes of respiratory failure in newborns, and its very toxic fluid could impair lung functions. The mortality rate of neonates who suffered from meconium aspiration syndrome (MAS) was $30-40 \%{ }^{5} \mathrm{~A}$ voluntary data collection for ECMO centers across the United States as well as other countries stated $93 \%$ of survival rate among 3547 MAS. $^{6}$ 
Table 1. Monitoring of some important patient's vital signs

\begin{tabular}{lrrrrr} 
& ECMO & ECMO & ECMO & ECMO & ECMO \\
\cline { 2 - 6 } & 0 & 10 & 20 & 40 & 80 \\
\hline - HR (/min) & 180 & 168 & 156 & 168 & 170 \\
- MAP $(\mathrm{mmHg})$ & 30 & 35 & 37 & 40 & 37 \\
- CVP $(\mathrm{mmHg})$ & 8 & 10 & 10 & 9 & 10 \\
- Dobutamin $\mu \mathrm{g} / \mathrm{kg} / \mathrm{min}$ & 10 & 5 & 5 & 5 & 5 \\
- PaO2 $(\mathrm{mmHg})$ & 49 & 284 & 196 & 161 & 107 \\
- PaCO2 $(\mathrm{mmHg})$ & 51 & 31 & 31.5 & 31.5 & 28.8 \\
" Lactate $(\mathrm{mg} / \mathrm{dl})$ & & & 2.6 & & \\
- pH & 7.15 & 7.38 & 7.55 & 7.52 & 7.53 \\
- $\mathrm{FiO}$ & 0.12 & 0.21 & 0.21 & 0.21 & 0.21 \\
" $\mathrm{RR}(/ \mathrm{min})$ & 20 & 14 & 10 & 10 & 10 \\
\hline
\end{tabular}

$\mathrm{MAP}=$ Mean arterial pressure $; \mathrm{CVP}=$ Central venous pressure

By using ECMO technique, the lung functions of the baby who aspirated meconium was put to rest for its restoration. ECMO is a technique for long-term extracorporeal circulating using heart-lung machine in order to ensure the exchange of $\mathrm{CO}_{2}$ and $\mathrm{O}_{2}$ in the body. Generally, ECMO device application includes vascular access catheter; connecting tube, servoregulating blood pump, an artificial lung (oxygenator), heat exchanger, and various measuring and monitoring devices. The main component of ECMO is the oxygen transport through an artificial membrane to blood (see Figure 1). ECMO in newborns is usually performed through vein to artery (VA) circulation, although vein to vein reviewed elsewhere. ${ }^{7}$

ECMO should be considered when conventional mechanical ventilation is not sufficient to treat respiratory failure in newborn. Even though the criteria for the use of ECMO differ from center to center, the option for this technique is based on predictive of potential mortality greater than $80 \%{ }^{8}$ Currently, the most widely used predictor of mortality as one of the parameters in indicating the use of ECMO is oxygenation index (OI). ${ }^{9}$ OI takes into account the degree of oxygen requirement and the mean airway pressure (MAP) needed to achieve ventilation. OI ranging from $40 \%$ to $50 \%$ was identified with $80 \%$ mortality. Better outcome with more aggressive approach, has been recomended where OI $>0.25$ should used as indicator for starting ECMO. OI is usually calculated as: $\mathrm{OI}=\left(\mathrm{MAP} \times \mathrm{FiO}_{2} \times 100 \mathrm{PaO}_{2}\right.$ 
OI in our patient was 0.88 . However, the baby for whom ECMO will be used should meet the following entry critetria: ${ }^{9,10}$

- Gestation is above 35 weeks and birth weight above 2000 grams

- Absence of intraventricular hemorrhage (outside germinal matrix, > grade I)

- Absence of abnormalities in blood coagulation

- Absence of major congenital malformation incompatible with life

- The use of ventilator is no longer than 10 days

- Reversible lung injury

- No major cardiac malformation

Like other sophisticated and high technologies, ECMO could only be offered at certain hospitals. Care of the patient on ECMO also requires attendance of ECMO personnel. The team work consists of intensivist, neonatologist, surgeons and technicians as well as consultants. Cardiologist and pulmonologist are essential. ${ }^{11,12}$

This case is the first baby who was successfully managed with ECMO support. ECMO program at 'Harapan Kita' National Cardiac Center has been initiated since 1991. However, due to constraints such as limited logistics and difficulty in obtaining referral (the patient was delivered too late or has no indication), we have only been able to handle nine cases (circulatory support or pulmonary support in three years) with only two neonates of ECMO survivor (decanulated).

The average ECMO performed was 4-5 days. In our case, ECMO was performed for only three days. An improvement in the patient can be seen directly from PO2 after the installation of ECMO. In this case, we found the improvement of her chest from her x-ray film and blood gas analysis: $\mathrm{PaO}_{2}$ increased and $\mathrm{PCO}_{2}$ decreased. Monitoring of organ functions such as heart, liver, and kidney remains was within normal limit.

The post-ECMO newborns should be monitored further for possible complications attributed to ECMO. Due to systemic heparinization, the risk for hemorrhage is very great. Intracranial bleeding in neonates is the most devastating complication and contributes to mortality and neurologic morbidity. Other complications are brain death, systemic hypertension, sepsis, and cerebral infarction. Mechanical complications such as oxygenator failure, raceway rupture, pump malfunction, clots and air in circuit and cannula malposition can occur. The ophthalmic status must be evaluated and before the patient is discharged from the hospital it is essential to detect signs of retrorental fibroplasia due to oxygen administration of high concentration. ${ }^{7-9}$

Finally, high technology of intensive care interventions are often singled out as an important factor contributing to escalating cost. In our patient, the total costs incurred for bypass ECMO for 5 days was 10,500 USD (1,500 USD/day for disposable and laboratory tests, 3,000 USD for the initiation of bypass). ${ }^{7}$

In summary, we recommend the use of ECMO for newborn with respiratory failure, especially due to meconium aspiration when conventional mechanical ventilation fails with a predicted mortality rate is higher than $80 \%$. 


\section{References}

1. Zwischenberg B, Barlett RH. An introduction to extracorporeal life support. Cardiopulmonary Support In Critical Care 1989;11-3.

2. Barlett RH. Current status of extracorporeal life suppot in neonatal respiratory failure. In: Springer,ed. Yearbook Of Intensive Care And Emergency Medicine 1995;2009-17.

3. Zobel G, Dacar D, Brigler B, Berger J, Metzler H. Prolonged extracorporeal support in a 2 year old boy after cardiac surgery. Intensive Care Med 1994; 20:368-70.

4. Extracorporeal life support organization. Ann Arbor: October 1994.

5. Wissmell TE, Bent RC. Meconium staining and meconium aspiration syndrome: unsolved issues. Pediatr Clin North Am 1993;40:995-81.

6. Cornish JD, Clark RH. Priciple and practise of veno-venous extracorporeal life support. Extracorporeal Life Support Organization 19989;87-109.

7. Mustafa I, Samudro H. Extracorporeal membrane oxygenation (ECMO). New technology or just a new tool for developing countries? Med J Indones 1997;6:82-91.

8. O'Rouke PP . Crone R. ECMO and conventional medical therapy in neonate with PPH of the newborn; a perspective randomized study. Pediatrics 1989;84;957-63.

9. O'Rouke PP. ECMO.Where have we been? Where are we going? Resp Care 1991;36: 683-92.

10. Rosanberg EM, Segiun JH. Selection criteria for use of ECLS in neonates. Extracorporeal Life Support Organization 1989;261-90.

11. Alpert BD, Clark RH. Neonatal intensive care. Washington: Space Lab Medical 1995; 113-8.

12. Barlett RH. Physiology of extracorporeal life support organization 1994;27-52. 